\title{
RESPIRATORY MANIFESTATIONS IN ENDOCRINE DISEASES
}

\author{
CODRUȚA LENCU ${ }^{1}$, TEODORA ALEXESCU ${ }^{2}$, MIRELA PETRULEA ${ }^{3}$, \\ MONICA LENCU ${ }^{3}$
}

\author{
${ }^{1}$ Department of Endocrinology, Iuliu Hatieganu University of Medicine and \\ Pharmacy, Cluj-Napoca, Romania \\ ${ }^{2} 4$ th Medical Department, Iuliu Hatieganu University of Medicine and Pharmacy, \\ Cluj-Napoca, Romania \\ ${ }^{3}$ Iuliu Hatieganu University of Medicine and Pharmacy, Cluj-Napoca, Romania
}

\begin{abstract}
The control mechanisms of respiration as a vital function are complex: voluntary - cortical, and involuntary - metabolic, neural, emotional and endocrine. Hormones and hypothalamic neuropeptides (that act as neurotrasmitters and neuromodulators in the central nervous system) play a role in the regulation of respiration and in bronchopulmonary morphology. This article presents respiratory manifestations in adult endocrine diseases that evolve with hormone deficit or hypersecretion. In hyperthyroidism, patients develop ventilation disorders, obstructive and central sleep apnea, and pleural collection. The respiratory abnormalities in hyperthyroidism as a result of the hypermetabolic action of thyroid hormones are hyperventilation, myopathy and cardiovascular involvement; recent studies have reported pulmonary arterial hypertension in Graves' disease, as a result of the association of several mechanisms. Thyroid hypertrophy can induce through compression of the upper airways dyspnea, stridor, wheezing and cough. The respiratory disorders in acromegaly are ventilatory dysfunction and sleep apnea, which contribute to an unfavorable evolution of the disease. Respiratory changes in parathyroid, adrenal and reproductive system diseases have been described. Respiratory disorders should be recognized, investigated and monitored by medical practitioners of various specialties (family physicians, internists, endocrinologists, pneumologists, cardiologists). They are frequently severe, causing an unfavorable evolution of the associated endocrine and respiratory disease.
\end{abstract}

Keywords: respiratory disorders, hypothyroidism, hyperthyroidism, acromegaly, hyperparathyroidism

\section{Introduction}

Modern studies over the past decades have demonstrated the implication of hormones in the physiological mechanisms of respiration and in the morphological maturation of the respiratory system components [1]. Endocrine control plays a role, alongside other factors, in the regulation/adaptation of respiration

Manuscript received: 16.03.2016

Received in revised form: 22.03.2016

Accepted: 21.04.2016

Address for correspondence: codruta 1mc@yahoo.com in some disorders. Respiration as a vital function is not regulated by specific hormones. Some hormones that include hypothalamic neuropeptides acting as neurotransmitters and neuromodulators have central effects, while others, through chemoreceptors or by direct action on the lungs and respiratory airways, have peripheral effects. Factors that are considered indirect, such as acid-base balance, body temperature, muscle or adipose mass, which can also be under hormonal control, can participate in the regulation of respiratory mechanisms [2]. 
The action of hormones on the respiratory system can be stimulating or inhibiting. Stimulating hormones are: $\mathrm{GH}$ (STH or somatotropic hormone), IGF-1 (insulin-like growth factor - 1), progesterone, testosterone, thyroxine, CRH (corticoliberin), leptin, neuropeptide Y (via neuropeptide Y-2 receptors), serotonin, histamine. Inhibiting hormones include somatostatin, TRH (thyroliberin), neuropeptide Y (via neuropeptide Y-1 receptors), dopamine [2]. Some hormones can act on the respiratory airways, inducing bronchodilation (epinephrine) or bronchoconstriction (histamine).

This article presents respiratory manifestations in endocrine diseases with glandular hyperfunction or hypofunction, but also of other causes. Pulmonary involvement in patients with endocrine pathology aggravates the disease prognosis, decreases the quality of life and can be a cause of death. Recognizing the "respiratory phenotype" in each endocrine disease is mandatory and requires emergency therapy.

\section{Thyroid diseases}

Thyroid hormones have complex metabolic effects that explain their intervention in the complex mechanism of respiration: they regulate protein, lipid and carbohydrate metabolism, control membrane enzyme activity, increase mitochondrial oxidative processes, modulate the transcription of many genes encoding myofibrillar and calcium-regulatory proteins in myofibers [3], play an important role in the development of the lungs and the maturation of pulmonary surfactant [4]. The alteration of thyroid function accompanied by sometimes life-threatening respiratory manifestations, which can be corrected by adequate therapy, is an argument supporting the importance of their knowledge.

\section{Hypothyroidism}

Clinically, patients have expiratory dyspnea induced by partial upper airway obstruction through edema and mucopolysaccharide infiltration, and speech disorders with a hoarse voice.

Lung volume is normal (non-obese) or slightly decreased (obese) [4].

Respiratory functional tests detect pulmonary hypoventilation and diminished ventilatory response to hypoxia and hypercapnia [5]. Studies have demonstrated that this major change in ventilation is of central origin, induced by reduced peripheral oxygen consumption and to a smaller extent, by an alteration of ventilatory mechanics [1].

The carbon monoxide diffusing capacity can be low in some hypothyroid patients, even non-obese with normal lung volume, a change that can be corrected by replacement therapy.

Reduced inspiratory and expiratory muscle tone demonstrated by the measurement of muscle pressure during maximal inspiration and expiration is correlated with the severity of hypothyroidism, with the TSH concentration level [6]. Myopathy is present in both types of myxedema: idiopathic and iatrogenic. Thyroxine replacement treatment significantly corrects myasthenia [7].

Diaphragmatic muscle dysfunction, another muscle change in hypothyroidism, is variable - mild, only limiting effort tolerance, and severe, with dyspnea and hypercapnia; it is conditioned by the severity of hypothyroidism, regardless of obesity or non-obesity [8]. Some studies suggest that diaphragmatic myasthenia has a double cause: myopathic and neuropathic (lesions of the phrenic nerve) $[6,9]$.

Hypothyroidism predisposes patients to sleep apnea (SA) (2). SA can be of obstructive and central origin. Obstructive sleep apnea syndrome (OSAS) has been diagnosed in $25 \%$ of patients with hypothyroidism. On the other hand, in $3.1 \%$ of OSAS patients, thyroid hypofunction has been detected [10]. Risk and causal factors of OSAS in hyperthyroidism include ventilatory dysfunction, oropharyngeal and upper airway infiltration with mucopolysaccharides and protein deposits, respiratory muscle asthenia, obesity, male sex, and advanced age [10]. Thyroid hormone therapy only improves OSAS; more rarely, it completely reverses it, after at least one year of treatment, particularly when other associated factors, such as obesity, are present [11]. Sleep apnea of central origin can also be identified in patients with hypothyroidism, usually in younger persons, having a rapidly favorable evolution after thyroxine replacement therapy $[10,12]$.

In subclinical hypothyroidism, the prevalence of sleep disorders is not different from euthyroidism [11].

Pleural collection is evidenced in $25 \%$ of patients with hypothyroidism [4]. This should be differentiated from pleural collections caused by disorders associated with hypothyroidism: pneumonia, cardiac failure, cirrhosis with ascites, malignant lesions [13]. Hypothyroid pleural collection is in small amounts (less than $1 / 3$ of the pleural cavity), unilateral or bilateral, serous or serosanguineous, transudate or exudate, in general non-inflammatory [14]. It is asymptomatic, more rarely it can induce restrictive pulmonary function [15]. Its pathophysiological mechanism is unknown; it probably develops through an increase of capillary permeability [14]. Hypothyroid pleural effusion resolves by hormone replacement therapy [14].

Hypothyroid coma, the final stage of untreated or insufficiently treated myxedema, evolves with severe respiratory failure as a result of hypoventilation, respiratory acidosis, upper airway obstruction through laryngeal edema and infiltration, respiratory muscle asthenia, decreased pulmonary surfactant, pulmonary and airway infections, reduced lung capacity through pleural effusion, respiratory center dysfunction, dyselectrolytemia, hypoglycemia, and arterial hypotension.

\section{Hyperthyroidism}

Patients with hyperthyroidism can experience effort and rest dyspnea [15]. In the context of associated 
cardiac disorders, these clinical manifestations can be more frequent and more severe [16,17].

High thyroid hormone levels induce hyperventilation and an increase of ventilatory response to hypoxia and hypercapnia, particularly through an increase of the central ventilatory drive [1].

Vital capacity is reduced due to respiratory muscle asthenia $[4,18]$.

A number of studies have identified an atopic background, with the elevation of serum immunoglobulin E in $30 \%$ of patients with Graves' hyperthyroidism. As a result, a warning should be given regarding the association of allergic bronchial asthma in hyperthyroid patients, the evolution of which can be aggravated by $\beta$-blockers administered for the control of hyperthyroidism [4].

Clinical observations have reported the association of hyperthyroidism, particularly Graves' disease, with pulmonary arterial hypertension [19,20]. Its causes are not completely understood; several mechanisms could be involved: secondary to an autoimmune process, through direct thyroid hormone action, the intervention of endogenous pulmonary vasodilators/vasoconstrictors on pulmonary vessels, a decrease of pulmonary surfactant production and function, and cardiovascular stimulation by the sympathetic-adrenal system $[19,20]$. Newborns of mothers with Graves' disease develop severe metabolic and growth disorders, constantly associated with severe pulmonary hypertension and respiratory failure [20].

Clinical studies have shown an association between Graves' disease treated with propylthiouracyl and Wegener's granulomatosis [4].

\section{Thyroid hypertrophy (goiter)}

The more frequent development of thyroid nodules in anterior position spares the trachea from their compressive action. Unilateral, posterior location or marked hypertrophy of one lobe causes tracheal deviation and upper airway compression. Patients experience dyspnea, stridor, wheezing and cough [21].

A large intrathoracic/substernal goiter determines the orthopneic position. The rapid growth of nodules accompanied by perinodular edema may induce severe acute respiratory distress [22,23].

\section{Parathyroid diseases}

Hyperparathyroidism

In secondary hyperparathyroidism in severe chronic renal disease or hemodialysis patients, nodular calcifications develop in the lung tissue, in the bronchial and pulmonary artery walls [4]. They are predominantly located in the alveolar septa, mainly in the lung apex. They are 3-10 mm in size, are accompanied by fibrosis and septal thickening, contain calcium salts and are better visualized by $\mathrm{CT}$ than by chest X-ray. In primary hyperparathyroidism, they are rare. In extensive forms, patients may have dyspnea, dry cough and restrictive dysfunction with hypoxemia. One third of the patients have associated pulmonary hypertension, which is not correlated with the presence or severity of pulmonary artery calcifications or with parathormone levels.

In primary hyperparathyroidism, particularly in parathyroid adenomas, in the context of systemic myasthenia, respiratory muscles are also affected; this is correlated with parathyroid hormone levels and serum calcemia.

\section{Parathyroid gland hypertrophy}

The increase in size of parathyroid glands by cysts or other benign and malignant tumors may cause tracheal compression with stridor and speech disorders.

\section{Hypoparathyroidism}

The consequence of deficient parathyroid hormone secretion or function is hypocalcemia and hyperphosphatemia with neuromuscular hyperexcitability [15]. Respiratory manifestations, which can be severe, are induced by tetany seizures (the most suggestive manifestation of neuromuscular hyperexcitability). Patients exhibit bronchospasm, diaphragmatic and chest contractions, laryngospasm (infants, children) [24].

\section{Growth hormone (GH) secretion disorders Acromegaly}

It is part of adult pathology. Clinical and biological manifestations are due to excessive GH secretion. The most frequent source of secretion is represented by pituitary adenomas and more rarely, by bronchial carcinoid tumors and small cell lung cancer. These secrete excessive growth hormone-releasing hormone $(\mathrm{GHRH})$, which stimulates GH secretion [4].

The clinical picture includes somatic changes (increase in the size of bones, soft tissue hypertrophy, characteristic facial appearance) and complex metabolic changes induced by the excess of GH and IGF-1 (insulinlike growth factor-1, mainly secreted by the liver, but also by other organs such as the lung, under the action of $\mathrm{GH}$ ) $[4,25]$.

Respiratory complications are frequent and severe, determining an unfavorable evolution with death in $25 \%$ of patients [26]. The morphoclinical and functional manifestations of the upper and lower airways, of the thoracic walls and lungs that cause an alteration of the respiratory function are: macroglossia, a hoarse voice through vocal cord thickening, laryngeal hypertrophy, sinus hyperpneumatization, nasal polyps, tracheal stenosis, nasopharyngeal cavity hypertrophy, submandibular salivary gland hyperplasia, thyroid hypertrophy (causing tracheal narrowing), increase in the size of the mandible and maxilla, hypopharyngeal swelling with inspiratory collapse, narrowing of the small airways exacerbated by infections, respiratory muscle weakness, changes in the vertebral bodies and intervertebral discs, kyphoscoliosis, increase in the volume and size of the lungs through hypertrophy and alveolar enlargement [4,27,28,29]. Extrathoracic airway obstruction is found in $30-35 \%$ of patients with acromegaly. 
Total lung capacity and vital capacity are increased, being correlated with the duration of the disease [30].

Sleep apnea is one of the most significant morbidities in acromegaly. Its presence is reported in $20-60 \%$ of patients [31]. Obstructive sleep apnea is due to upper airway obstruction through oropharyngeal tissue hypertrophy, macroglossia, inspiratory collapse of the hypopharynx, increase in the size of bones and neck circumference. Pituitary ablation or treatment with octreotide (a somatostatin analogue) improves clinical manifestations. Central sleep apnea, also frequent in acromegaly, occurs in the context of an alteration of the central control mechanism of ventilation. These patients have higher GH and IGF-1 levels than patients with obstructive sleep apnea, as well as a higher ventilatory response to hypercapnia [4].

\section{Adrenal gland diseases}

\section{Endogenous Cushing's syndrome}

Autonomous endogenous hypercortisolism is caused by ACTH-secreting pituitary adenomas, adrenal adenomas or adenocarcinomas, as well as by ectopic ACTH secretion from small cell lung carcinomas, carcinoid tumors, gastrinomas, pheochromocytomas or pancreatic islet cell carcinomas. Cortisole levels are significantly higher in the case of ectopic ACTH hypersecretion or adrenal neoplasia, compared to pituitary neoplasia [4].

The connection with respiratory manifestations is the predisposition of hypercortisolism to opportunistic pulmonary infections, particularly with Aspergillus, Nocardia, Critococcus, Pneumocystis or Mycobacterium tuberculosis.

Hypercortisolemia favors the state of hypercoagulability, increasing the risk of thromboembolism.

\section{Addison's disease}

Primary adrenocortical insufficiency, Addison's disease, has an autoimmune etiology in $70-80 \%$ of cases in developed countries. In poor countries, it is of tuberculous etiology in the majority of the patients.

\section{Pheochromocytoma}

A catecholamine-secreting tumor, it can sometimes be complicated by pulmonary edema induced by an increase in pulmonary capillary permeability in the context of elevated blood catecholamine levels [1].

\section{Reproductive system diseases}

Studies on the physiology and pathophysiology of the respiratory system carried out decades ago demonstrate the implication of reproductive hormones in respiratory mechanics [1,2]. However, there are few reproductive system diseases evolving with respiratory manifestations.

Malignant and benign ovarian tumors (Meigs syndrome) develop unilateral or bilateral pleural collections, sometimes accompanied by ascites [15]. Choriocarcinoma or Sertoli-Leydig cell tumors may induce lung metastases.

Cases of endometriosis with specific tissue in the diaphragm or pleura, causing recurrent catamenial pneumothorax, have been described [1]

Obstructive sleep apnea (OSAS) has a high prevalence in polycystic ovary syndrome, $17-44 \%$, or in the postmenopausal period, $2.7 \%$ (its prevalence in premenopause is $0.6 \%)$ [2,32].

\section{References}

1. Milla CE, Zirbes J. Pulmonary complications of endocrine and metabolic disorders. Paediatr Resp Rev. 2012;13:23-28.

2. Saaresranta T, Polo O. Hormones and breathing. Chest. 2002;122:2165-2182.

3. Nafae RM, Mohammed MA, Morsi AF, Ibrahim DA. Thyroid function in respiratory failure patients. Egypt J Chest Dis Tuberc. 2014;63:513-521.

4. Zimmerman L. Pulmonary complications of endocrine diseases. In: Broaddus VC, Mason RJ, Ernst JD, King TE, Lazarus SC, Murray JF, Nadel JA, Slutsky AS, Gotway MB (eds). Murray and Nadel's. Textbook of respiratory medicine. 6th Edition, Philadelphia: Elsevier Saunders, 2016; chapter 95: 1671-1678.

5. Ladenson PW, Goldenheim PD, Ridgway EC. Prediction and reversal of blunted ventilatory responsiveness in patients with hypothyroidism. Am J Med. 1988;84:877-883.

6. Siafakas NM, Salesioutou V, Filaditaki V, Tzanakis N, Thalassinos N, Bouros D. Respiratory muscle strength in hypothyroidism. Chest. 1992;102(1):189-194.

7. Weiner M, Chansow A, Szidon P. Reversible respiratory muscle weakness in hypothyroidism. Br J Dis Chest. 1986;80:391-395.

8. Martinez FJ, Bermudez-Gomez M, Celli BR. Hypothyroidism. A reversible cause of diaphragmatic dysfunction. Chest 1989; 96 : 1059-1063.

9. Laroche CM, Cairns T, Moxham J, Green M. Hypothyroidism presenting with respiratory muscle weakness. Am Rev Respir Dis. 1988;138:472-474.

10. Lin CC, Tsan KW, Chen PJ. The relationship between sleep apnea syndrome and hypothyroidism. Chest. 1992;102(6):16631667.

11. Grunstein RR, Sullivan CE. Sleep apnea and hypothyroidism: mechanisms and management. Am J Med. 1988;85:775-779.

12. Millman RP, Bevilacqua J, Peterson DD, PackAI. Central sleep apnea in hypothyroidism. Am Rev Respir Dis. 1983;127:504-507. 13. Douglass RC. Pleural effusions with myxedema. Arch Intern Med. 1983;143(12):2334.

14. Gottehrer A, Roa J, Stanford GS, Chernow B, Sahn SA. Hypothyroidism and pleural effusions. Chest. 1990;98:11301132.

15. Brüssel T, Matthay MA, Chernow B. Pulmonary manifestations of endocrine and metabolic disorders. Clin Chest Med. 1989;10(4):645-653.

16. Klein J. Thyroid hormone and the cardiovascular system. Am J Med. 1990;88:631-637.

17. Martos Velasco J. Primary pulmonary hypertension associated with hyperthyroidism. Aten Primaria. 1992;9:163-164.

18. Siafakas NM, Salesiotou B, Filaditaki B, Tzavara J, Thalassinos N. Respiratory muscle strength in hyperthyroidism before and after treatment. Am Rev Respir Dis. 1988;137(abstract): A71.

19. Marvisi M, Brianti M, Marani G, Del Borello R, Bortesi ML, Guariglia A. Hyperthyroidism and pulmonary hypertension. Respir Med. 2002;96(4):215-220.

20. Ismail HM. Reversible pulmonary hypertension and isolated right-sided heart failure associated with hyperthyroidism. J Gen 
Intern Med. 2007;22(1):148-150.

21.Torchio R, Gulotta C, Perboni A, Ciacco C, Guiglielmo M, Orlandi F, et al. Orthopneea and tidal expiratory flow limitation in patients with euthyroid goiter. Chest. 2003;124:133-140.

22. Noppen M, Poppe K, D’Haese J, Meysman M, Velkeniers B, Vincken W. Interventional bronchoscopy for treatment of tracheal obstruction secondary to benign or malignant thyroid disease. Chest. 2004;125:723-730.

23. Meysman M, Noppen M, Vincken W. Effect of posture on the flow-volume loop in two patients with euthyroid goiter. Chest. 1996;110:1615-1618.

24. Shoback D. Clinical practice. Hypoparathyroidism. N Engl J Med. 2008;359:391-403.

25. Sjögren K, Liu JL, Blad K, Skrtic S, Vidal O, Wallenius V, et al. Liver-derived insulin-like growth factor I (IGF-I) is the principal source of IGF-I in blood but is not required for postnatal body growth in mice. Proc Natl Acad Sci USA. 1999; 96:70887092.

26. Melmed S. Acromegaly and cancer: not a problem? J Clin Endocrinol Metab. 2001;86:2929-2934.

27. Colao A, Ferone D, Marzullo P, Lombardi G. Systemic complications of acromegaly: epidemiology, pathogenesis, and management. Endocr Rev. 2004;25(1):102-152.

28. Brody JS, Fisher AB, Gocmen A, DuBois AB. Acromegalic pneumonomegaly: lung growth in the adult. J Clin Invest. 1970;49:1051-1060.

29. Garcia-Rio F, Pino JM, Diez JJ, Ruiz A, Villasante C, Villamor J. Reduction of lung distensibility in acromegaly after suppression of growth hormone hypersecretion. Am J Respir Crit Care Med. 2001;164:852-857.

30. Camilo GB, Guimaraes FS, Silva DP, Mogami R, Kasuki L, Gadelha MR, et al. Pulmonary function testing and chest tomography in patients with acromegaly. Multidisc Respir Med. 2013;8(1):70.

31. Akkoyunlu ME, Ilhan MM, Bayram M, Tasan E, Yakar F, Özcelik HK, et al. Does hormonal control obviate positive airway pressure therapy in acromegaly with sleep-disordered breathing? Respir Med. 2013;107:1803-1809.

32. Keefe DL, Watson R, Naftolin F. Hormone replacement therapy may alleviate sleep apnea in menopausal women: a pilot study. Menopause. 1999;6:196-200. 